\title{
La readaptación ideológica del orden neoliberal en el discurso menemista*
}

\author{
The ideological re-adaptation of neoliberal order \\ in the Menemist discourse \\ Hernán Fair** \\ Universidad de Buenos Aires, Buenos Aires, Argentina
}

Recibido: 27 de marzo de 2014. Aprobado: 22 de septiembre de 2014.

\begin{abstract}
Resumen
El trabajo analiza el proceso de readaptación ideológica del neoliberalismo en la Argentina menemista de los años 90 . En una primera parte, se examina los múltiples cambios ideológicos y políticos en el escenario internacional, incorporando algunas contribuciones para el desarrollo de un análisis político del discurso neoliberal, desde la perspectiva de Laclau. En la segunda parte, se coloca atención en las particularidades del caso argentino durante el primer gobierno de Carlos Menem. En ese marco, se analiza las interpelaciones presidenciales a una pluralidad de tradiciones sedimentadas y las estrategias para legitimar el orden neoliberal, concentrándose en el juego de desarticulaciones y rearticulaciones discursivas en torno al significante democracia. Por último, analiza la interacción dialéctica entre el plano verbal y extralingüístico del discurso de Menem, aportando elementos para elucidar la eficacia interpelativa y los límites de la hegemonía menemista.
\end{abstract}

Palabras clave: menemismo, neoliberalismo, análisis político del discurso.

Este artículo se deriva de una investigación más amplia presentada como tesis de Doctorado en Ciencias Sociales, Universidad de Buenos Aires, marzo de 2013, bajo la dirección del Dr. Javier Balsa. Ella fue financiada íntegramente con una beca doctoral del Consejo Nacional de Investigaciones Científicas y Técnicas (CONICET). Agradezco los comentarios y críticas de los evaluadores anónimos de esta revista.

** Doctor en Ciencias Sociales en la Universidad de Buenos Aires (UBA). Investigador del Consejo Nacional de Investigaciones Científicas y Técnicas (CONICET-UNQ). Docente e investigador en la Universidad Nacional de Quilmes (UNQ) y en la UBA. Correo electrónico: hernanfair@conicet.gov.ar 


\begin{abstract}
The paper analyzes the process of ideological re-adaptation of neoliberalism in Menemist Argentina of the 90s. The first part examines the multiple ideological and political changes on the international level, incorporating Lacau's contributions to the development of a political analysis of neoliberal discourse. In the second part, the focus is on the particularities of the Argentinean case during Carlos Menem's first presidency. Within this framework, presidential interpellations are analyzed as part of a plurality of sedimented traditions and the strategies used to legitimize the neoliberal order, focusing on the discursive game of disarticulation and re-articulation around the meaning of democracy. Finally, it analyzes the dialectical interaction between the verbal and extra-linguistic plane from Menem's speech, contributing to elucidate the interpellative efficacy and the limits of menemist hegemony.
\end{abstract}

Keywords: menemism, neoliberalism, political analysis of discourse.

\title{
Introducción
}

El presente trabajo tiene por objetivo analizar el proceso de readaptación ideológica del neoliberalismo en Argentina menemista de los años 90. Aunque una pluralidad de estudios han examinado la construcción de la hegemonía menemista, escasean las investigaciones centradas en el discurso de legitimación presidencial del nuevo rumbo, sobre todo desde una perspectiva de análisis político del discurso. En ese marco, si bien se ha destacado la concepción conservadora (Borón, 1991), procedimental-liberal (Bonetto, 2012) o neoconservadora (Bonnet, 2008) del menemismo, no se han investigado las múltiples interpelaciones discursivas y la compleja articulación ideológica que estableció el discurso de Menem entre los valores neoliberales, liberal-democráticos y conservadores y su encadenamiento a la tradición nacional-popular y a la doctrina peronista. Se ha concluido, en dicho contexto, que el menemismo realizó un práctico abandono de toda relación con la dimensión nacional-popular del peronismo de posguerra (Aboy Carlés, 2001) y con los aspectos vinculados a la participación política y las interpelaciones a la dimensión social de la democracia (Bonetto, 2012, p. 210). De esta forma, no se ha profundizado en la relación del discurso de Menem con la visión comunitarista y social del peronismo histórico. En el mismo sentido, sus vínculos con los cambios en el nuevo orden internacional han sido llamativamente relegados en la bibliografía, y los escasos 
análisis que han destacado las relaciones entre la discursividad menemista y el fenómeno más amplio de la globalización (Martínez, 2012; Piñero, 2001), no han examinado su compleja interpelación a una pluralidad de tradiciones yuxtapuestas y sus estrategias discursivas para legitimar las reformas neoliberales.

El artículo se propone examinar estos aspectos del discurso menemista. En una primera parte, se analizan los múltiples cambios ideológicos y políticos en el escenario internacional, que adquieren un papel central al actuar como condicionantes generales de las reformas neoliberales en Argentina. En ese marco, se incorporan algunas contribuciones originales tendientes al desarrollo de un análisis político del discurso neoliberal, desde la perspectiva teórica de Ernesto Laclau. En la segunda parte, se analiza el proceso de readaptación ideológica del orden neoliberal en el discurso de Menem, examinando las interpelaciones presidenciales a una pluralidad de tradiciones sedimentadas y las estrategias para legitimar el nuevo orden. De manera específica, se coloca el eje en el juego de desarticulaciones y rearticulaciones discursivas en torno al significante democracia, examinando las estrategias para legitimar, política y socialmente, la readaptación de la ideología neoliberalconservadora a las particularidades del caso argentino. Por último, se analiza la interacción dialéctica entre el plano verbal y extralingüístico del discurso presidencial, aportando elementos para elucidar la eficacia interpelativa y los límites de la hegemonía menemista.

La hipótesis principal sostiene que el discurso de Menem, obligado a legitimar los profundos cambios político-ideológicos frente a sus partidarios de tradición nacionalpopular y frente a una sedimentada doctrina peronista, realizó una compleja readaptación del neoliberalismo al escenario local. En ese marco, logró reformular la clásica concepción nacional-popular del peronismo histórico, apelando una compleja mixtura ideológica que encadenó aspectos de la tradición participativa, popular y social de la democracia, con elementos ortodoxos en el plano económico, pluralistas-liberales en lo político y conservadores en lo social. Esta mixtura interpelativa se extendió al plano internacional, encadenando equivalencialmente a la democracia política con la democracia económica y el fenómeno de mundialización, conocido como globalización.

\section{Marco teórico-metodológico}

El marco teórico-metodológico de este trabajo se basa en un enfoque de construccionismo social que rechaza toda forma de objetivismo, determinismo y esencialismo, destacando el papel histórico, relativo y contingente de lo social. De manera específica, 
se toman como base las herramientas de la teoría del discurso de Ernesto Laclau (2005 y 1993), asumiendo las siguientes premisas:

1. El discurso define y otorga significación (parcial) a lo social, de modo tal que presenta una dimensión material e intersubjetiva y una capacidad formativa y transformativa. En ese marco, el discurso es capaz de construir y reformular las identidades políticas sedimentadas.

2. La realidad social es producto de una lucha hegemónica que se expresa mediante la articulación simbólica de cadenas equivalenciales (articulaciones de palabras), la delimitación de fronteras políticas (confrontación antagónica de palabras) y la presencia de significantes flotantes (palabras clave en debate), que se disputan el sentido legítimo del orden comunitario.

3. La disputa por el sentido del orden se condensa en la dinámica política en torno a determinados significantes vacíos (palabras claves), que logran encadenar múltiples significaciones y encarnar, de forma simbólica, el orden ausente.

Esta perspectiva, no obstante, presenta algunos problemas para operacionalizar sus categorías (Balsa, 2011). En dicho marco proponemos complejizar sus aportes, incorporando una serie de elementos adicionales:

1. Aunque el discurso adquiere un sentido amplio que incluye sus aspectos lingüísticos y extralingüísticos, estos planos no actúan en un mismo registro. En ese contexto, se puede establecer una distinción analítica entre el plano lingüístico (verbal o textual) del discurso y el plano extralingüístico (extraverbal o extratextual), definiendo al primero como discurso en sentido estricto y al segundo como discurso en sentido amplio.

2. En la dinámica histórico-política, el plano lingüístico del discurso asume una relación de interacción dialéctica con el plano extralingüístico y sus diferentes niveles (prácticas sociales, marco institucional, modelo de acumulación, políticas públicas, hechos físicos y biológicos identidades, tradiciones, creencias, imaginarios sociales, etc.).

3. En los procesos políticos, el plano discursivo-extralingüístico puede concordar, o bien ingresar en contradicción fáctica, con el plano lingüístico, coadyuvando al 
éxito o contribuyendo a expresar los límites históricos de las interpelaciones ideológicas.

4. Aunque lo social es producto de una lucha hegemónica entre una multiplicidad de agentes, algunos actores políticos asumen un papel contextualmente privilegiado para construir interpelaciones discursivas eficaces, de modo tal que adquieren un rol central en la construcción de hegemonías.

5. Determinados actores políticos, en ese sentido, pueden ser posicionados estratégicamente en el plano de la construcción de hegemonías, mientras que otros actores pueden ser ubicados en el plano de la recepción, sin que ello suponga que estos últimos no construyen activamente hegemonía.

6. La figura del Presidente adquiere un papel privilegiado para generar identificaciones y, potencialmente, reformular identidades y tradiciones existentes, debido a su posición estructural y su poder político, institucional y simbólico. Esta capacidad performativa se potencia bajo regímenes presidencialistas con elevados poderes de prerrogativa, tradiciones históricas de partidos pragmáticos y liderazgos personalistas y verticalistas, y aspectos propios de la personalidad, como la capacidad dialógica, argumentativa y el carisma.

7. La teoría de la hegemonía puede ser articulada con el análisis de una serie de tradiciones político-culturales que se encuentran parcialmente sedimentadas y objetivadas en textos previos. En ese marco, el uso no esencialista de tradiciones históricas como el liberalismo, la democracia, el republicanismo y el conservadurismo, contribuyen a profundizar el abordaje de la "perspectiva de la tradición" (Aboy Carlés, 2001), una dimensión ontológica de toda identidad; aspecto que ha sido destacado, de hecho, por el propio Laclau (1993).

En base a estas especificaciones, en el siguiente trabajo proponemos posicionar la figura de Menem como un agente interpelador clave, que es capaz, bajo ciertas condiciones extralingüísticas, de reformular las identidades parcialmente sedimentadas y objetivadas. Tomando como eje los discursos oficiales del Presidente durante su primer mandato (1989-1995) y una selección de declaraciones reproducidas en los principales medios de prensa gráfica nacional (Clarín, La Nación y Página 12), nos concentraremos en las interpelaciones ideológicas del discurso menemista a una pluralidad de tradiciones sedimentadas en textos previos. De manera específica, nos centraremos en lo que Balsa (2011) define como el juego dialógico de desarticulaciones y rearticulaciones del discur- 
so, que permite a cierto actor político clave desarticular determinada cadena de equivalencias para rearticularla a una nueva cadena, con significados diferentes ${ }^{1}$.

\section{La reorganización ideológica y política en el escenario internacional de las últimas décadas}

A partir de mediados de la década de los 70 se produjeron una serie de transformaciones histórico-políticas clave, que promovieron un giro ideológico en los centros de poder, repercutiendo a escala mundial. El origen de este cambio nos remonta a tres acontecimientos:

1. La crisis del Estado benefactor keynesiano: esta crisis, producto de la caída de los precios internacionales del petróleo (1973) y la imposibilidad de articular el crecimiento económico con el control de la tasa de inflación (estanflación), potenció la expansión de las ideas neoliberales, que venían difundiéndose desde mediados de la década de los 40 .

2. La creación de la Comisión Trilateral: esta organización, fundada en 1973, congregó a dirigentes de empresas multinacionales, grandes banqueros, dirigentes políticos y algunos académicos, en una serie de encuentros que tenían por objeto diagnosticar los principales problemas del planeta y establecer cursos futuros de acción política. En ese marco, en 1975 los intelectuales Huntington, Crozier y Watanuki elaboraron un influyente informe, denominado La crisis de la democracia. En él se asumía un diagnóstico de 'ingobernabilidad democrática' como consecuencia de un 'exceso de demandas' sociales, producto, a su vez, de una 'participación ampliada' de la ciudadanía. Estas 'excesivas' demandas sociales impedirían la correcta toma de decisiones por parte de los Estados y, por consiguiente, su pérdida de legitimidad política para garantizar el orden (gobernabilidad) (Murillo, 2008, pp. 85 y ss.).

3. El triunfo anti-Somoza en Nicaragua: como lo ha destacado Ezcurra (1998), a partir del triunfo de los antisomocistas en Nicaragua, los Estados Unidos, aunque mantenían su objetivo de combate al comunismo, realizarían un giro ideológico. Desde entonces dejarían de apoyar activamente a los golpes militares de la región

1 Para una aplicación de esta estrategia metodológica al caso argentino, véase Fair (2013). 
(como lo habían hecho en Chile en 1973 y en Argentina en 1976), temerosos de los posibles efectos indeseados de repolitización de las masas.

En el marco de estas transformaciones en el orden internacional, la llegada al poder de Ronald Reagan (1980-1983), en los Estados Unidos, promovería profundos cambios ideológicos y políticos. Desde entonces, la superpotencia mundial asumiría dos elementos novedosos:

a. La defensa del orden democrático-liberal, articulando los valores neoconservadores con una visión formalista de la democracia capitalista, en clave neoliberal.

b. La difusión de estos valores 'democráticos' y 'civilizadores' a escala mundial.

En ese marco, el gobierno de Reagan dejó de lado la clásica doctrina de seguridad nacional y comenzó a difundir la nueva doctrina de la "democratización global" (Ezcurra, 1998).

\section{Las mutaciones político-ideológicas de los 90: neoconservadurismo, formalismo democrático y neoliberalismo globalizado}

Hasta fines de los 80 , persistía a escala mundial una fuerte disputa política e ideológica entre la concepción liberal-formal y la concepción popular-social de la democracia (ya sea en su versión socialdemócrata o nacional popular), a lo que se sumaba la visión anticapitalista del marxismo. En la década siguiente, sin embargo, el (neo)liberalismo lograría reprimir la polisemia constitutiva a una sola concepción: la procedimental y formal, de estirpe neoliberal en lo económico y conservadora en lo social. En ese marco, democracia pasó a ser equivalente a democracia liberal, en el sentido de respeto a los valores del capitalismo neoliberal (libre mercado), defensa del Estado de derecho y del orden representativo-parlamentario y resguardo formal de las libertades, derechos y garantías individuales.

Esta transformación ideológica solo fue posible bajo ciertas condiciones de posibilidad. Ya hemos mencionado el papel de los Estados Unidos extendiendo los valores de la democracia (neo)liberal a escala mundial. Debemos considerar, además, una serie de 
acontecimientos adicionales que se produjeron entre mediados de la década de los $80 \mathrm{y}$ principios de los 90:

1. La democratización institucional en la Unión Soviética y el derrumbe del bloque soviético: desde mediados de la década de 1980, bajo el liderazgo de Gorbachov, se produjo en la Unión Soviética un proceso de democratización institucional que concluyó con el derrumbe del socialismo y de su modelo burocrático y represivo, y el fin de la Guerra Fría.

2. La profundización de la crisis del Estado benefactor: luego del fracaso de los planes heterodoxos de estabilización, hacia fines de los 80 se profundizó la crisis del modelo benefactor, tanto en sus versiones keynesianas como desarrollistas. Esta crisis se materializó en América Latina en un estancamiento económico, acompañado por una profundización de las tasas de inflación. Además, se sumó a ello el problema del endeudamiento externo con los organismos multilaterales de crédito, el giro de inversiones hacia los países centrales y los problemas estructurales internos (economía concentrada, aparato estatal colonizado por los grupos de poder, industrias poco competitivas), que incentivaron un aumento del déficit fiscal y crecientes niveles de ineficiencia, burocratización estatal y falta de competitividad.

3. La extensión del proceso de mundialización: un tercer factor clave se vincula a la revolución tecnológica (en particular, en la informática y las telecomunicaciones) que profundizó los intercambios comerciales y financieros y la velocidad de circulación de las transacciones. Ambos fenómenos, con antecedentes en los 60 y 70, se potenciaron con la apertura financiera y la deslocalización de las mercancías, promoviendo una creciente interconexión mundial y modernización económica, que tomaría el nombre de globalización. Además, estos cambios reforzaron el papel de las empresas multi y transnacionales y de los organismos multilaterales, promoviendo la pérdida de soberanía de los Estados-nación. Finalmente, la creación e institucionalización de organismos supranacionales y normativas regionales y mundiales de intercambio económico y cooperación internacional, con antecedentes en la inmediata posguerra, profundizaron la interconexión entre los Estados y los límites a la soberanía estatal2.

2 Aunque el poder militar de Estados Unidos no decayó, ni el Consejo de Seguridad de la ONU pudo controlar su expansión unilateral, a partir del fin de la Guerra Fría se profundizaron los intercambios económicos (financieros y comerciales) y culturales entre los países y el orden internacional incorporó una lógica de mayor difusión del poder. Estos cambios se potenciaron en 1992, con la firma del Tratado de la Unión Europea, y en 1995, con la entrada en vigencia del Mercado Común del Sur (MERCOSUR). 
4. La expansión de la democratización institucional en América Latina y parte de Europa: a fines de los 80 se profundizó, en una porción de Europa (Grecia, España y Portugal) y de América Latina (en particular, en el Cono Sur), la crítica a las prácticas antiliberales y autoritarias de los regímenes dictatoriales. En los países de tradición nacional-popular, además, se extendió la crítica neoconservadora a la lógica movimientista, al tiempo que se fortalecía el discurso de democratización institucional y respeto a las libertades individuales ${ }^{3}$.

5. Cambios ideológicos y organizativos en los organismos multilaterales de crédito: desde mediados de los 80 se produjo un cambio ideológico en los organismos multilaterales de crédito. Así, el FMI, que hasta entonces solo reclamaba la implementación de los planes de estabilización, comenzó a demandar también la aplicación de un conjunto de reformas estructurales, en el marco del llamado Plan Baker (1985). Al mismo tiempo, el Banco Mundial, que hasta comienzos de la década de los 80 financiaba proyectos específicos, con prescindencia del marco de políticas públicas, comenzó a condicionar sus préstamos monetarios a la realización de reformas de mercado. Los nuevos préstamos condicionados buscaban que los gobiernos de América Latina, algunos de los cuales se hallaban en moratoria y requerían equilibrar sus economías, obtuvieran las divisas necesarias para abonar sus deudas en los términos previstos por los acuerdos ${ }^{4}$.

\section{La primera etapa de la mutación ideológica y política}

Bajo estas condiciones de posibilidad, a las que podemos sumar la fragmentación e individuación de las identidades y la extensión de la lógica hiperconsumista, que promovieron la apatía política y un creciente individualismo hedonista y competitivo (García Delgado, 1994), durante los 90 los ideólogos neoliberales, liderados por el poder político y cultural de los Estados Unidos y por una pluralidad de intelectuales orgánicos de los organismos multilaterales, usinas de economistas, empresarios, banqueros, dirigentes políticos y referentes mediáticos, edificaron y difundieron un reformulado discur-

3 Un discurso que también haría mella dentro de la politología dominante en nuestra región, al compás de los estudios sobre la Transición y luego la consolidación de la democracia, que conducirían a la crítica a las democracias delegativas o decisionistas.

4 Sobre las transformaciones en los organismos multilaterales, véanse Murillo (2008) y Ezcurra (1998, pp. 55-65). 
so neoliberal, de matriz neoconservador ${ }^{5}$. Esta construcción hegemónica se estructuró mediante cinco elementos primordiales:

a. La articulación de las ideas neoconservadoras con un discurso liberal de matriz evolucionista y pacifista, difundido a partir de la famosa tesis de Fukuyama de la democracia (neo)liberal como el fin de la historia evolutiva de la humanidad y los antiguos enfrentamientos ideológicos de la Guerra Fría ${ }^{6}$.

b. La difusión de un discurso cientificista, en el que las ideas neoliberales eran consideradas científicas y objetivas, en base al saber de la ciencia matemática.

c. La difusión de un discurso imposibilista, que enfatizaba la ausencia de alternativas válidas a las reformas estructurales y la imposibilidad de oponerse a los postulados del 'mercado', en una lógica no exenta de la fabricación de un temor al caos económico y social (ya sea hiperinflacionario o devaluatorio).

d. La articulación del neoliberalismo con el discurso de la globalización, expresada en el proyecto del Presidente estadounidense Bill Clinton de conformar una 'alianza global para la democracia', conocida como Área para el Libre Comercio de las Américas (ALCA).

5 Como señala Bonnet, el neoconservadurismo y el neoliberalismo no son conceptualmente equivalentes, aunque, en la práctica, adquirieron una relación de asimilación que los hizo indistinguibles. En ese marco, a diferencia del conservadurismo clásico, centrado en valores antiliberales, los gobiernos neoconservadores se caracterizaron por asumir una concepción afín al liberalismo económico y político (2008, p. 254).

6 Aunque la idea del liberalismo económico ligado al progreso de la civilización se hallaba presente desde Hayek (1978, p. 44), Fukuyama profundizó este aspecto, al compás del derrumbe del comunismo y el fracaso de las dictaduras militares y los gobiernos autoritarios (iliberales). En ese marco, al que el autor suma los avances de la ciencia natural, materializados en la revolución tecnológica e informacional, el teórico estadounidense se reapropiará de la tesis positivista de Hegel del Estado liberal como el Fin de la Historia, y del cosmopolitismo de Kant, para referirse a la democracia liberal como la etapa final de evolución universal de la humanidad. Pero además, desde una reinterpretación hegeliana del aspecto irracional, se referirá a la democracia liberal como una respuesta al "deseo de reconocimiento" (el "tymos") de los hombres como individuos autónomos, libres, iguales y con dignidad. Finalmente, en el contexto de fin de la Guerra Fría, crisis del keynesianismo, declive de los nacionalismos económicos y étnicos y del colonialismo europeo, y bajo la difusión de los organismos supranacionales, extenderá este principio al plano internacional a partir de una reinterpretación de Hegel (y de Kant) desde los aportes de Kojeve, en el que los países liberales se 'reconocen' entre sí en condiciones soberanas de 'libertad' e 'igualdad' (Fukuyama, 1991). La tesis de Fukuyama parece mostrar una apertura del realismo neoconservador hacia aspectos idealistas. 
e. La capacidad líquida de los organismos multilaterales de crédito para realizar préstamos financieros condicionados a la aplicación de reformas y ajustes neoliberales, en el marco de la escasez de divisas y los desequilibrios fiscales y monetarios de los países latinoamericanos.

\section{Las estrategias de desarticulación y rearticulación ideológica del discurso neoliberal}

Bajo estos condicionamientos, a los que debemos sumar el uso de la violencia física para reprimir las protestas opositoras, podemos afirmar, desde el análisis político del discurso, que durante la década de los 90 el discurso neoliberal realizó una triple estrategia de desarticulación y rearticulación ideológica:

1. A partir de la frontera política liberalismo $=$ democracia versus Estado benefactor + comunismo $=$ dictadura, desarticuló a los Estados benefactores de los valores sustantivos e igualitarios de la democracia y los rearticuló al autoritarismo y la violencia, al no respetar los ideales de la democracia liberal. Al mismo tiempo, hizo lo propio con el comunismo, al que rearticuló con el totalitarismo. En ese contexto, siguiendo a Hayek, ambos fenómenos fueron igualados bajo lógicas antidemocráticas?

2. A partir del encadenamiento libre mercado $=$ democracia $=$ libertad, profundizó la articulación del liberalismo político con el liberalismo económico, integrando al libre mercado con los valores de la democracia y la libertad individual. De este modo, se reapropió del concepto de libertad, para rearticularlo a la libertad individual para comerciar y consumir, reforzando la defensa del régimen democrático y la frontera política contra la interferencia del Estado autoritario y violento8.

7 Hayek articulaba al keynesianismo y a la socialdemocracia con 'el peligro de repetir la suerte de Alemania' bajo el nazismo y a ambos fenómenos con el 'colectivismo' soviético. En ese marco, el Estado benefactor era equivalente al nazismo, el fascismo y el socialismo, y ambos al 'espectro del totalitarismo'. De modo tal que si liberalismo económico era encadenado a libertad individual ('sociedad libre') y 'prosperidad', keynesianismo era equivalente a la eliminación de aquellos valores (1978, pp. 29 y ss.).

8 En este punto, los nuevos ideólogos neoliberales reformularon a Hayek, quien sostenía que "cuando la democracia deja de ser una garantía de la libertad individual, puede muy bien persistir en alguna forma bajo un régimen totalitario" (1978, p. 102). 
3. Encadenó al (neo)liberalismo con el fenómeno de la globalización (económica y tecnológica), adoptando una concepción evolucionista y pacifista en el orden internacional.

De este modo, a partir de la cadena equivalencial libre mercado + globalización $=$ democracia + libertad + modernización (tecnología, consumo) + progreso + felicidad + paz social, realizó un triple proceso ideológico:

a. Desarticuló a las ideas desarrollistas de su histórico encadenamiento con significantes como modernización y desarrollo, para apropiarse de la valoración positiva de los cambios tecnológicos e informacionales y revincularlos a las reformas neoliberales y a la necesidad de difundirlos a escala mundial, en una especie de cruzada global en defensa de las ideas modernizadoras.

b. En el marco de la crisis del Estado benefactor y del socialismo soviético, desarticuló a las alternativas marxistas y keynesianas de su concepción evolucionista, para reencadenarlas a valores negativizados, relacionados a una economía atrasada, cerrada y aislada del mundo, y a un pasado que no solo había fracasado, sino que había sido superado por la historia. Finalmente, en el marco del fenómeno de la globalización, reforzó el encadenamiento del neoliberalismo a un inevitable proceso de inserción al nuevo orden internacional, rearticulado a un imaginario de modernización, progreso, desarrollo y avance o evolución mundial de la sociedad.

c. Desactivó la validez de las críticas de las corrientes marxistas, nacional-populares y cepalianas, a las formas de dependencia y dominación imperial, reforzando el encadenamiento del discurso liberal con una concepción pacifista del orden internacional, entendido como un mundo solidario, pacífico e integrado, carente de relaciones de poder y antagonismo entre las naciones.

Incorporando una distinción analítica entre fronteras político-institucionales y político-económicas, podemos sintetizar estas operaciones ideológicas en el siguiente esquema:

a. Frontera político-institucional: Estado benefactor (populista) $=$ comunismo $=$ autoritarismo $=$ totalitarismo versus liberalismo $=$ democracia $=$ libertad $($ de elegir $y$ de consumir) $=$ pluralidad (de ideas). 
b. Frontera político-económica en el plano nacional: Estado benefactor $=$ inflación $=$ burocracia $=$ déficit fiscal $=$ corrupción $=$ atraso $=$ decadencia $=$ pasado versus liberalismo económico $=$ libertad $=$ eficiencia $=$ estabilidad $=$ crecimiento $=$ modernización $=$ progreso $=$ avance $=$ futuro.

c. Frontera político-económica en el plano internacional: Estado benefactor (populista $)$ comunismo $=$ economía aislada $=$ economía atrasada $=$ economía cerrada $=$ fracaso $=$ pasado versus liberalismo $($ económico $)+$ globalización $=$ inserción internacional $=$ integración al mundo $=$ paz $=$ modernización $=$ progreso $=$ evolu ción $=$ futuro.

En un contexto de crisis efectiva del Estado benefactor (en sus distintas variantes) y debacle del socialismo soviético, que concluiría en la caída del Muro de Berlín (1989) y el derrumbe del comunismo (1991), y bajo las transformaciones económicas, tecnológicas e institucionales de la globalización, durante la década de los 90 los ideólogos neoliberales lograron extender a escala internacional el discurso ortodoxo en lo económico, liberal-formal en lo político y neoconservador en lo social, al tiempo que decretaban la ausencia de alternativas válidas y la imposibilidad de ir en contra de las 'fuerzas impersonales' del 'mercado. El éxito de este discurso, convertido en sentido común, fue particularmente notable en nuestra región, y se materializó en la represión ideológica (tendencial) de las alternativas que habían dominado durante gran parte del siglo XX, basadas en la defensa del modelo benefactor (ya sea en su versión nacional popular o socialdemócrata) y las tradiciones desarrollistas, neomarxistas y antiimperialistas. Incluyendo a las concepciones de la teoría de la dependencia, que representaban el máximo aporte de nuestra región al pensamiento político y los estudios internacionales (Bonetto, 2012, p. 212; Bernal Meza, 2003).

\section{La institucionalización del orden neoliberal}

La reorganización ideológica de la década de los 90, funcional a las demandas de las incipientes empresas multi y transnacionales y los grandes bancos para extender a nivel planetario la circulación del capital financiero y comercial, concluyó con una serie de cambios organizativos, que institucionalizaron y consolidaron la hegemonía neoliberal: 
a. La firma del Consenso de Washington: a fines de 1989, Estados Unidos distribuyó y difundió un decálogo de reformas, bajo el nombre de Consenso de Washington, que servía como una especie de guía intelectual para alcanzar los objetivos de la estabilización, la modernización y el crecimiento económico de los países latinoamericanos, frente al fracaso del 'estatismo'.

b. El Tratado de Maastricht: en 1992, los países europeos realizaron una serie de acuerdos que restringieron la emisión monetaria autónoma de los bancos centrales y fijaron como objetivo central la estabilización macroeconómica ${ }^{10}$.

Poco después, se crearían nuevos organismos para promover la difusión del libre mercado a nivel mundial (Organización Mundial del Comercio, Tratado de Libre Comercio de América del Norte), potenciando junto al papel de los foros económicos mundiales en Davos (Suiza) y la formación del Grupo de los Ocho, la institucionalización y la expansión global del neoliberalismo.

\section{Segunda etapa: reformulación ideológica de mediados de la década de los 90}

\section{La profundización del giro neoconservador}

En una segunda etapa, que se extiende durante la segunda mitad de la década de 90, se produjo una nueva reformulación ideológica en los centros de poder mundial, que profundizó el aspecto neoconservador del neoliberalismo, incorporando lo que podemos denominar la etapa 'social'. Dos fueron sus principales condiciones de posibilidad:

a. Los efectos sociales regresivos de las reformas de primera generación: en el marco de la aplicación del capitalismo salvaje neoliberal, a mediados de la década de los

9 El decálogo de las políticas del Consenso de Washington incluía el disciplinamiento fiscal, la reducción del gasto público, la unificación de la tasa de cambio, la liberalización del mercado, el impulso a la inversión extranjera directa, la privatización de empresas públicas, la desregulación de la economía, el respeto a la propiedad privada, la reforma del régimen tributario y la liberalización del sistema financiero.

10 Estas transformaciones serían adoptadas también por algunos países de nuestra región, entre ellos la Argentina, que en 1992 reformó la Carta Orgánica del Banco Central. 
90 se extendieron los 'costos sociales' de las reformas, materializadas en el aumento de las tasas de desempleo, subempleo, desigualdad y pauperización social.

b. El levantamiento zapatista en Chiapas y la profundización de las protestas sociales: el 1 de enero de 1994, como una reacción a las reformas de mercado y la aprobación del NAFTA, se produjo un levantamiento zapatista en Chiapas (México). Desde entonces, en diversos países de la región se profundizaron las protestas sociales contra los efectos regresivos de las políticas neoliberales.

En el marco de estos efectos colaterales, los ideólogos neoliberales realizaron una nueva reformulación y aggiornamiento de la ortodoxia. Esta transformación, con antecedentes en los documentos del Banco Mundial de los primeros años de la década, se sistematizaría e institucionalizaría en 1997, bajo el nombre de reformas de segunda generación o Consenso pos-Washington (Stiglitz, 1998). La nueva mutación ideológica, también conocida como Consenso de Santiago (Guiñazu, 2000), se tradujo en el apoyo monetario y organizativo del Banco Mundial a una serie de políticas asistencialistas y focalizadas, dirigidas a combatir los efectos sociales regresivos de las reformas. Asumiendo un discurso neoconservador, que se extendería también al Banco Interamericano de Desarrollo (BID) y sería difundido por una pluralidad de intelectuales orgánicos, se sostenía la necesidad de aplicar políticas focalizadas, con el objetivo explícito de generar mayor trabajo y reducir la pobreza y el objetivo implícito de evitar posibles efectos de repolitización de los sectores populares, afectados por el crecimiento de la pobreza y el desempleo, producto de las reformas de la primera mitad de la década de los $90^{11}$. De modo tal que, al igual que a comienzos de la década anterior, se retomaba el temor neoconservador a las formas de participación social de las masas y sus riesgos sobre la gobernabilidad política, lo que implicaba la necesidad de compensar los costos de las reformas mediante estos programas asistencialistas (Murillo, 2008, pp. 85 y ss.; Grassi, 2004, pp. 178-197; Ezcurra, 1998, pp. 67-81 y ss.).

\section{Las instituciones también importan}

Junto a la profundización del giro neoconservador en lo social, las reformas de segunda generación resaltaron la necesidad de consolidar (eficientizar) los cambios reali-

11 Un segundo aspecto de este giro ideológico fue la extensión de la teoría del capital humano y su énfasis en el valor de la educación de los sectores marginalizados (Murillo, 2008; Ezcurra, 1998, pp. 118 y ss.). 
zados mediante la implementación de transformaciones institucionales (Guiñazú, 2000). Estas reformas se vinculan a una serie de condiciones de posibilidad:

a. Las prácticas iliberales de los liderazgos latinoamericanos: una porción de los liderazgos políticos de nuestra región, como Menem en Argentina, Fujimori en Perú y Collor de Melo en Brasil, se habían caracterizado por aplicar políticas neoliberales, pero reñidas con los valores de la democracia liberal. En ese marco, las prácticas 'delegativas' y 'patrimonialistas', como la corrupción, el clientelismo y el nepotismo, junto a la concentración de poder en el Ejecutivo y las restricciones a la libertad de prensa y de expresión, actuaron como caldo de cultivo para las críticas (neo)liberales, que acusaban a estos liderazgos de atentar contra la democracia y la consolidación de las reformas de mercado.

b. Las crisis económicas en el sudeste asiático y en Rusia: luego de la devaluación en México (1994), las crisis económicas en Tailandia, Corea e Indonesia (1997), extendidas a Rusia (1998) y luego a Brasil (1999), hacían peligrar el destino de las reformas neoliberales y su promesa de estabilización y crecimiento, y obligaban a pensar en alternativas para enfrentarlas.

Bajo estos condicionamientos, los ideólogos neoliberales comenzaron a señalar que los crecientes problemas económicos y sociales de nuestra región solo podrían solucionarse mediante la profundización de las reformas económicas pendientes (entre ellas, un mayor ajuste monetario), complementadas con la aplicación de reformas institucionales. Junto a la estabilización ortodoxa, estas reformas en los mecanismos de funcionamiento institucional (desde una mayor división de poderes, hasta la creación de marcos regulatorios para evitar la formación de monopolios) se traducirían en mayor confianza, previsibilidad o 'seguridad jurídica' para el sector privado, todo lo cual promovería el ingreso de inversiones extranjeras y el 'visto bueno' del mercado para garantizar la estabilidad macroeconómica, el crecimiento y la modernización. A partir del Informe del Banco Mundial de 1997 sobre el Desarrollo Mundial comenzó a insistirse en que las instituciones también eran 'importantes' (Payne, 2003), y que las causas de las crisis regionales no eran producto de las falacias teóricas y epistemológicas de la ideología neoliberal, algo que se hallaba fuera de discusión, sino que se debía a deficiencias en la organización institucional de las reformas, o a su insuficiente implementación ${ }^{12}$.

12 Además, desde el Banco Mundial se comenzó a insistir en la idea de capital social, relacionado al fortalecimiento (empoderamiento) de las instituciones de la sociedad civil (en particular, las ONG), en detrimento del papel del Estado (Murillo, 2008; Guiñazú, 2000). En el mismo sentido, intelectuales como Amartya Sen comenzaron 


\section{Las transformaciones ideológicas del neoliberalismo desde el análisis político del discurso}

A partir de estas transformaciones, las tres cadenas equivalenciales del discurso hegemónico se condensaron en una amplia y solidificada frontera política, que encadenó los valores neoliberales, neoconservadores y liberal-democráticos, conformando una megafrontera política que contrapuso:

Estado benefactor $=$ comunismo $=$ autoritarismo $=$ totalitarismo + economía aislada $=$ atrasada $=$ cerrada + inflación $=$ burocracia $=$ déficit fiscal $=$ corrupción $=$ pasado $=$ fraca so versus liberalismo $=$ democracia $=$ libertad $($ de elegir $y$ de consumir $)=$ pluralidad $($ de ideas $)+$ libre mercado $=$ eficiencia $=$ estabilidad $=$ crecimiento + globalización $=$ inserción internacional $=$ integración al mundo $=$ modernización $=$ progreso $=$ evolución $=$ avance = futuro.

En los términos del análisis político del discurso, podemos decir que la macrocadena equivalencial del neoliberalismo se expandió hasta abarcar nuevos significados, de manera tal que ahora:

Reformas estructurales (privatizaciones, apertura, desregulación, flexibilización laboral) + planes de estabilización (reducción del gasto público, equilibrio fiscal y monetario), se complementaba con políticas focalizadas + reformas institucionales (división de poderes, marcos regulatorios) $=$ confianza o seguridad jurídica $=$ ingreso de inversiones externas, lo que se traducía en estabilidad + crecimiento + modernización + paz social.

Mediante estas reformulaciones, que mixturaban las ideas neoliberales con los discursos liberal-republicanos de gran parte de los sectores críticos de las reformas ${ }^{13}$, se mantenía la promesa del demorado futuro venturoso, que 'derramaría' la paz, la libertad y la felicidad en todo el planeta.

a destacar el papel de los valores morales y las capacidades individuales, de modo tal que se dejaron de lado los condicionantes estructurales (García Delgado, 2003, p. 173).

13 El propio Hayek (1978) se refería a la necesidad de crear una "estructura legal cuidadosamente pensada" para incentivar las "fuerzas de la competencia" (p. 64), y se extendía sobre la importancia del "Estado de derecho" para crear normas previsibles para los individuos (pp. 103 y ss.). Este plano institucional, sin embargo, ha sido destacado por la Escuela de Virginia o Public Choice, liderada por Buchanan y Tullock (véase Morresi, 2008, pp. 26-29). 


\section{La readaptación ideológica del neoliberalismo en el discurso menemista}

Una vez en el poder, Menem dejó de lado las ambigüedades de su discurso de campaña, convirtiéndose en uno de los más entusiastas defensores del orden neoliberal. En ese marco, las fronteras político-discursivas del neoliberalismo conservador fueron asumidas como horizontes conceptuales por su gobierno. Sin embargo, como señala Morresi (2008, p. 73), cada país realizó una adaptación del neoliberalismo a sus propias tradiciones históricas y políticas. Si en países como Chile el enemigo central era el socialismo, en la Argentina los ideólogos neoliberales situaron como enemigo principal al populismo, asociado al modelo económico del peronismo de posguerra. El menemismo, sin embargo, asumió sus propios rasgos, de acuerdo a las tradiciones vernáculas en las que debía ser legitimado (básicamente, la tradición nacional-popular y la doctrina peronista). Para analizar las particularidades ónticas del discurso menemista, resulta relevante realizar una distinción analítica entre el plano lingüístico y el extralingüístico del discurso. Como veremos, existirán ciertas discordancias entre los dichos de Menem y sus acciones (discursivas) concretas.

\section{El plano verbal del discurso de Menem}

La defensa de la democracia (neo)liberal y su articulación con el fenómeno de la globalización

Desde el plano lingüístico del discurso, el Presidente se posicionaba como un líder plenamente democrático (liberal), que respetaba el conflicto y la pluralidad de ideas y promovía la defensa de la democracia, tanto a nivel local como en el plano internacional. En ese marco, partía desde una perspectiva formal de la democracia que lo articulaba equivalencialmente a los valores de la libertad, la convivencia y la aceptación del conflicto y la pluralidad de ideas (Página 12, 7 de abril de 1993, p. 2. y 30 de abril de 1993, p. 5; Clarín, 23 de julio de 1993, p. 3 y 31 de julio de 1993, p. 7). En el mismo sentido, posicionaba a su gobierno como "defensor de la libertad de expresión", el respeto al disenso y la división de poderes (Página 12, 26 de junio de 1993, p. 4).

En una segunda operación, la discursividad menemista encadenaba al liberalismo político con el económico, de modo tal que, junto al "total respeto a la libertad de prensa" (La Nación, 26 de junio de 1993, p. 8) y el "abandono de las tentaciones confron- 
tativas" (Página 12, 8 de junio de 1993, p. 4), se debía garantizar el establecimiento de la "democracia económica". Ello implicaba "ir eliminando trabas burocráticas y dilaciones inadmisibles" (La Nación, 2 de mayo de 1993, p. 4).

Ambos elementos se encadenaban, a su vez, al fenómeno de la globalización. En ese marco, el Presidente destacaba la vinculación entre la democracia, el proceso de globalización mundial y el resguardo de las libertades fundamentales. En el mismo sentido, adoptaba una concepción minimalista de los derechos humanos, reducida al resguardo de los derechos civiles y políticos (Página 12, 8 de junio de 1993, p. 4).

Esta cadena equivalencial se extendía al fomento de la paz en el plano internacional, a partir de la "participación militar en las misiones de paz y el restablecimiento del orden jurídico internacional, bajo la autoridad de las Naciones Unidas". En ese contexto, asumiendo una postura pacifista, Menem se situaba como un exponente de la defensa de la democracia, la paz y los derechos humanos. En la misma sintonía, reclamaba "una salida democrática para Cuba", para "garantizar la democracia, la libertad y el respeto irrestricto a los derechos humanos"14 (Clarín, 17 de julio de 1993, p. 2).

En el plano social, el discurso menemista incorporaba una concepción neoconservadora. En ese marco, criticaba con frecuencia la legitimidad de las movilizaciones sociales de los sectores opositores, destacando que "a la Argentina no la vamos a arreglar con marchas y movilizaciones, la vamos a arreglar trabajando" (Página 12, 7 de abril de 1993, p. 2).

Finalmente, los encadenamientos concluían con la articulación del liberalismo político, el neoliberalismo y el fenómeno de la globalización, a partir de la adopción de un discurso evolucionista, a favor de la modernización y el progreso. En ese contexto, Menem destacaba que "la libertad de expresión ha sido una de las manifestaciones más sensibles en diez años de democracia", para luego señalar que "con libertad, hemos emprendido y llevado a cabo la reforma del Estado, condición necesaria para el verdadero despegue nacional" (La Nación, 26 de junio de 1993, p. 8).

14 Esta especie de idealismo pragmático, que se materializaba en el envío de tropas a las misiones de paz de la ONU y se potenciaba con el discurso de la Argentina como un país-potencia y con la concepción del mundo como una aldea global, al menos matiza la tesis de Escudé sobre el realismo periférico en el plano internacional. Para una interesante crítica desde una perspectiva construccionista, véase Piñero (2001). 


\section{La incorporación de valores conservadores}

Junto a la asunción de un discurso (neo)liberal, las alocuciones de Menem incorporaban valores típicamente conservadores, como las apelaciones a Dios, el amor, la fe, las interpelaciones habituales a los "hermanos y hermanas" y la revalorización de la paz, el orden, la unidad y el reencuentro como objetivos centrales (Presidencia de la Nación, 8 de julio de 1989, p. 14; 11 de septiembre de 1989, pp. 72-74, 8 de julio de 1991; 26 de agosto de 1991, p. 140; 15 de septiembre de 1992, p. 232 y 12 de mayo de 1993, p. 7). El mismo discurso pacificador sería empleado para legitimar la firma de los indultos a las Fuerzas Armadas (1989 y 1990) y las alianzas con el establishment local e internacional, de tradición neoliberal. Además, reforzando el aspecto más conservador de la doctrina peronista (condensado en la idea de comunidad organizada), Menem resaltaba la dimensión humanista y cristiana del peronismo, que rechazaba la lucha de clases y tenía por objeto el logro de la paz y la unidad nacional. Finalmente, el discurso conservador era traspolado al plano internacional, destacando la existencia de un mundo pacífico y solidario, en el que predominaba el orden, la paz, la solidaridad y una idea de comunitarismo entre todas las naciones (la comunidad internacional).

\section{Las apelaciones a la concepción social de la democracia: la economía popular de mercado}

Ahora bien, lo interesante es que los discursos de Menem mantenían, a su vez, algunos residuos del macrodiscurso nacional-popular del peronismo histórico. El Presidente, en efecto, debía mantener el apoyo de los sectores de tradición más movimientista (entre ellos, los sindicalistas y trabajadores de la Unión Obrera Metalúrgica), además de integrar a los sectores populares, principales afectados por las políticas neoliberales. En ese marco, su discurso en el poder conservó algunos ejes típicos de la concepción popular-social de la democracia, aunque reformulados para ser adaptados al orden neoliberal.

Por un lado, el discurso verbal de Menem preservó las típicas apelaciones del peronismo histórico al pueblo, la justicia social y, en ocasiones, a la idea de una democracia social. Sin embargo, a diferencia de los discursos de finales de la década de los 80 , el pueblo dejó de estar ligado al movimiento peronista, a lo nacional y popular, de modo tal que se vació de contenido la tradicional concepción movimientista-popular, que encadenaba al líder $=$ nación $=$ pueblo . Por el otro, realizó una hábil reformulación ideo- 
lógica, que vinculó a la estabilidad monetaria, producto del éxito estabilizador de la Ley de Convertibilidad (1991), con un aspecto sustancial, que favorecía materialmente a los trabajadores y sectores populares, ya que concluía con el impuesto inflacionario y promovía, de este modo, un aumento de los salarios, menores índices de pobreza y mayores niveles de producción y consumo popular. Estos significantes se vinculaban, finalmente, al principio básico de la justicia social del peronismo y a una novedosa economía popular de mercado.

Finalmente, los discursos de Menem, al tiempo que rechazaban la lógica movimientista, retomaban aspectos referidos a la participación social del pueblo en la toma de decisiones. En ese marco, los Programas de Propiedad Participada (PPP), que prometían a los trabajadores despedidos de las empresas públicas un porcentaje cercano al 10\% de las acciones, eran legitimados en base al otorgamiento de una "participación activa" a los trabajadores en el proceso de "transformación" del Estado. Desde las alocuciones presidenciales, estos programas lograban convertir a los trabajadores "de proletarios en propietarios", que eran "dueños de las empresas" y de "su propio destino", y al propio "pueblo" en verdadero partícipe de lo público (Presidencia de la Nación, 26 de abril de 1991, pp. 93-94; 23 de mayo de 1991, p. 133 y 14 de junio de 1991, p. 184).

Del mismo modo, la implementación de políticas sociales, pese a ser focalizadas, implicaba, para el Presidente, priorizar la lucha contra la pobreza y el encuentro con los pobres, para alcanzar una auténtica política social (Presidencia de la Nación, 1 de agosto de 1990; 25 de abril de 1991, p. 89; 26 de abril de 1991, pp. 93-94; 2 de mayo de 1991, p. 120; 23 de mayo de 1991, p. 133; 14 de junio de 1991; 7 de enero de 1993; 22 de septiembre de 1993, pp. 425-426; 12 de noviembre de 1993, p. 121). Ello significaba, desde el discurso verbal de Menem, asumir un modelo de crecimiento en favor de la "Argentina real", la llamada "economía popular de mercado", que se oponía tanto al "capitalismo salvaje" como al "dirigismo burocrático". De esta manera, se promovía un "capitalismo social y humanizado", que garantizaba la "justicia social” (Página 12, 7 de abril de 1993, p. 2; La Nación, 2 de mayo de 1993, p.4), reenviando a elementos típicos de la concepción popular-social del peronismo histórico. En ambos casos, que actuaban como una respuesta frente a las demandas participacionistas del sindicalismo peronista, y frente a las demandas sensibilistas de la estructura partidaria, el discurso menemista les otorgaba a estos sectores una capacidad agentiva, posicionándolos como protagonistas del nuevo orden y no como meros espectadores pasivos, de modo tal que potenciaba la vinculación de su discurso con la lógica participativa de la democracia ${ }^{15}$.

15 Asumiendo esta perspectiva participativa, en 1993 el menemismo convocó a un plebiscito popular para reformar la Constitución y permitir la reelección presidencial. En ese marco, Menem reclamará una "oportunidad al 


\title{
El plano extralingüístico del discurso de Menem
}

\author{
Las prácticas políticas e institucionales iliberales
}

Desde el plano extraverbal del discurso, las ambigüedades eran mayores. Por un lado, el menemismo garantizó elecciones limpias y transparentes en todos los comicios de la década. Además, en líneas generales, respetó la libertad de expresión y de asociación y mantuvo presentes y activos los partidos políticos, los sindicatos y el Congreso, distinguiendo al caso argentino de otros más extremos, como el peruano (Fujimori), así como de la propia tradición autoritaria del peronismo histórico. Sin embargo, el menemismo se caracterizó por mantener una lógica tensional con los valores liberal-democráticos. En ese sentido, realizó una concentración decisionista del poder en la figura del presidente, controlando el Poder Judicial y relegando el papel autónomo del Congreso, a partir de la reforma de la Corte Suprema (abril de 1990) y el abuso de los decretos de necesidad y urgencia, los vetos parciales y totales y la legislación delegada (Baldioli y Leiras, 2010). Además, hizo uso, en varias oportunidades, de métodos violentos, basados en amenazas de muerte y agresiones físicas a periodistas y estudiantes opositores. De hecho, desde diciembre de 1990, hasta julio de 1993, hubo más de 100 denuncias de periodistas agredidos, 50\% de las cuales fueron acompañadas por acciones físicas (Clarín, 22 de julio de 1993). También se produjeron sospechosas muertes de testigos de la corrupción del poder político, y hasta se intentó sancionar, en 1993, una ley para espiar a los opositores (Página 12, 30 de junio de 1993, p. 7). Por último, durante su mandato el Presidente no dudó en limitar por decreto los paros sindicales a la expresa autorización del Poder Ejecutivo (octubre de 1990) y, en ocasiones (como en el Santiagueñazo de 1993), reprimió la protesta social mediante el uso de las Fuerzas Armadas, negándoles legitimidad a sus adversarios políticos. En ese marco, su discurso verbal a favor del respeto a la libertad y la pluralidad, ingresaba en contradicción fáctica con sus prácticas discursivas iliberales.

Las prácticas políticas reñidas con los valores neoliberales y neoconservadores

El menemismo se caracterizó por asumir una visión neoliberal, de tinte neoconservador en lo social. En ese marco se ubica la aplicación sistemática de las reformas promercado, las limitaciones institucionales a las formas de movilización social y las po-

pueblo" para que "decida sobre las cuestiones fundamentales de la vida nacional" y, de este modo, "se convierta en protagonista de su propio destino" (Pagina 12, 15 de mayo de 1993, p. 4). En la misma línea, en su discurso del 1 de mayo, propuso realizar una reforma política que "elimine las listas sábana". Este proyecto implicaba "establecer un modelo institucional más racional, más participativo y, en definitiva, más plenamente democrático" (La Nación, 2 de mayo de 1993, p. 4).

124 Si Somos Americanos. Revista de Estudios Transfronterizos 
líticas focalizadas, orientadas a mantener el orden, la paz y la gobernabilidad política. Además, el menemato se insertó acríticamente al nuevo orden internacional, respondiendo a las demandas de los Estados Unidos sobre desarme nuclear y participación en las misiones de paz. Sin embargo, pese a ser uno de los países cuyas reformas fueron más radicales, el gobierno de Menem no fue plenamente neoliberal. En ese sentido, debemos destacar el efectivo aumento del gasto público, las políticas de regulación selectiva en la industria y los vaivenes para desregular las obras sociales, que generaron resquemor en algunos núcleos ortodoxos.

Del mismo modo, cuando observamos las prácticas sociales e institucionales del menemismo, el discurso conservador nos muestra también algunas contradicciones fácticas. Bonnet ha señalado, en ese sentido, que el menemismo asumió una versión autóctona del neoconservadurismo, que articuló elementos neoliberales con otros de tradición conservadora, como el "compromiso de los valores de la familia patriarcal cristiana, en su lucha contra el aborto, la apología de la autoridad y el orden social". A ello le agregó una particular cosmovisión cínica, afín con la lógica posmoderna (Bonnet, 2008, p. 255). Es precisamente en este último sentido que debemos destacar los límites de los estudios que se concentran en la visión meramente conservadora de su liderazgo. En efecto, el menemismo llevó hasta el paroxismo una lógica de la frivolidad, la exhibición y la ostentación pública del consumo lujoso, reñido con las tradiciones conservadoras, e incluso con las experiencias neoconservadoras de Reagan y Thatcher. Además, aunque Menem era coherente en su oposición irrestricta al aborto, y expresaba verbalmente la importancia de los valores familiares, durante su mandato se divorció de su esposa e hizo gala de su seducción con las mujeres y su gusto por la noche y la lógica farandulezca, en un sentido que contrariaba a la sobriedad y la austeridad conservadoras. Un ejemplo de estas prácticas sociales discordantes se observó en el manejo del Presidente de una Ferrari a alta velocidad en las rutas argentinas, pero también en su frivolidad, su estilo de vestir (con trajes de colores llamativos y de primera marca), su afición por las mujeres y la noche, la participación pública habitual en partidos de tenis, básquet y fútbol, y su reconocida amistad con las figuras del mundo del espectáculo, con quienes compartía un lugar en las revistas de la farándula y fiestas en Miami y Punta del Este, en las que se comía pizza y se bebía champán francés.

Las prácticas políticas e institucionales opuestas al discurso de democratización social y popular

Aunque Menem afirmaba que su modelo promovía una economía social y popular, que otorgaba una participación activa a los trabajadores, al tiempo que incrementaba 
los salarios y reducía la pobreza, fomentando la justicia social, las prácticas discursivas ingresaban en tensión con esta concepción. Así, no solo los PPP eran diferidos y parcialmente aplicados, sino que además se rechazaban aspectos centrales de la tradición nacional-popular, como la lógica movimientista y los principios igualitarios del peronismo histórico, que garantizaban pleno empleo y derechos sociolaborales universales a los trabajadores. De hecho, en los 90 se produjo un aumento fáctico de la inequidad social, tasas inéditas de desempleo y una creciente pauperización de los trabajadores y sectores populares, a lo que se sumaba un modelo desindustrializador y privatista, antagónico del Estado benefactor de posguerra.

\section{La brecha entre el decir y el hacer, los contra argumentos de Menen y los límites interpelativos del discurso menemista}

Como hemos visto, el discurso de Menem presentaba discordancias entre el plano lingüístico y las prácticas sociales extralingüísticas. El Presidente buscaba sortear esta brecha, respondiendo a las críticas provenientes desde los diferentes sectores sociales. En ese marco:

a. Frente a las críticas desde posiciones liberales, se resituaba como un líder plenamente democrático, que respetaba los valores pluralistas de la democracia liberal. En ese sentido, aunque en ocasiones no dudaba en descalificar a los opositores, acusándolos de "violentos", "subversivos", "terroristas", "sediciosos", "agitadores marxistas" y "salvajes", en todo momento intentará atribuir una legitimidad democrático-liberal a su Gobierno. En ese contexto, destacará que "hay un respeto absoluto a la libertad de expresión", y que "vale la pena poner la otra mejilla frente a las críticas" (Página 12, 26 de junio de 1993, p. 3). También señalará que el gobierno promueve "la democracia y la libertad" (Clarín, 31 de julio de 1993, p. 7) y que, incluso, "este es el gobierno que más libertad ha dado". En ese sentido, resaltará que "yo avalo, como Presidente, las críticas, porque ayudan, en una democracia como la que vivimos" (Clarín, 23 de julio de 1993, p. 3). Por último, retrucando a las críticas desde las fuerzas político-partidarias, en ocasiones acusará a la propia oposición en el Congreso de tener "una suerte de miedo al debate, de intolerancia a la democracia y a la libertad" (Página 12, 7 de abril de 1993, p. 2).

b. En respuesta a las críticas desde posiciones conservadoras, Menem apelaba con frecuencia a "Dios", el "amor" y la "hermandad" y se reposicionaba desde un dis- 
curso pacifista, en favor del orden, la paz, la unidad y la reconciliación nacional e internacional.

c. En respuesta a los reclamos desde posiciones ortodoxas, Menem reasumía una firme defensa de las reformas y ajustes estructurales y de la inédita alianza con los Estados Unidos.

d. Finalmente, como respuesta a los reclamos de los sectores de tradición peronista y nacional popular, el Presidente se reposicionaba dentro de la doctrina histórica y vinculaba al modelo económico, en particular tras la estabilización monetaria, con la defensa del trabajo, la producción nacional, el consumo popular, el aumento de los salarios y la reducción de las tasas de pobreza e indigencia. . En ese marco, reenviaba a la tradición humanista y social del peronismo, relacionando a las reformas con una economía "social" o "popular", que promovía la "justicia social" y la "participación" activa de los trabajadores.

No obstante, hemos señalado que las políticas públicas y las propias prácticas sociales de Menem, en ocasiones ingresaban en contradicción fáctica con sus argumentaciones. Las interpelaciones menemistas, además, en ocasiones "chocaban" con tradiciones y creencias fuertemente arraigadas, que limitaban su eficacia performativa. En ese sentido, no llama la atención que emergieran una serie de contradiscursos refractarios, que criticarían el hegemonismo, la frivolidad, la falta de austeridad y los crecientes niveles de desempleo y desindustrialización. Además, frente a las habituales prácticas antirepublicanas del gobierno, se expandirá un contradiscurso moralista, crítico de la corrupción y la inmoralidad del menemismo.

Durante el segundo gobierno de Menem (1995-1999), estos discursos sintomáticos, que dejaban sin cuestionar los fundamentos nodales del modelo, convergerían en la formación de la Alianza (1997), expresión local de la reformulación ideológica del neoliberalismo conservador y sus reformas de segunda generación.

\section{Conclusiones}

Analizamos en este trabajo algunos aspectos referidos al discurso de legitimación del orden neoliberal, concentrándonos en la particular readaptación ideológica que le 
imprimió el menemismo en la Argentina de los años 90. Vinculamos estas transformaciones a un proceso más amplio de reorganización política, que se llevó a cabo en las últimas tres décadas en el escenario internacional. Bajo una pluralidad de condicionamientos económicos, sociales, institucionales, físicos y organizacionales, durante la década de los 90 el discurso neoliberal realizó una nueva metamorfosis, para encadenarse equivalencialmente con los valores positivizados atribuidos a la democracia liberal y el fenómeno de la globalización. Una vez en el poder, Menem adoptó estos valores culturales difundidos desde los centros de poder mundial. Sin embargo, les impuso su propio sello. En ese marco, necesitado de legitimar las transformaciones frente a sus partidarios de tradición nacional-popular y peronista, y procurando ampliar el arco de apoyos hacia otros sectores sociales, realizó una compleja interpelación ideológica a una pluralidad de tradiciones yuxtapuestas, incluyendo referencias a ideas democráticas, liberales y conservadoras y a aspectos doctrinarios de tradición peronista y neoliberal. En ese contexto, el Presidente asumió una concepción típicamente liberal de la democracia, vinculada a la defensa de las libertades individuales y la aceptación del conflicto y la pluralidad. Este discurso era encadenado a las reformas neoliberales, en tanto equivalentes a la libertad económica y a valores positivizados, como la estabilidad, el crecimiento y a un imaginario de modernización social. A su vez, la concepción de la democracia (neo)liberal era extendida al ámbito internacional, promoviendo una inserción acrítica al nuevo orden global y a sus valores evolucionistas de desarrollo, progreso y avance mundial. Finalmente, integraba este discurso con elementos típicamente conservadores, enarbolando un discurso pacifista y consensual que se traspolaba a la búsqueda de la paz, la unidad, el consenso y la solidaridad en el seno de la comunidad internacional (la "aldea global").

Pero vimos también que, junto al discurso (neo)liberal, Menem no dejaba de interpelar a los sectores de tradición nacional-popular y peronista. En ese marco, su discursividad recuperaba algunos aspectos de la concepción popular-social de la democracia. Así, desde las alocuciones presidenciales, los programas de propiedad participada le otorgaban una participación activa a los trabajadores y al pueblo en el proceso de transformación nacional, convirtiéndolos en propietarios y haciéndolos protagonistas y partícipes necesarios de su propio destino. La estabilidad económica, por su parte, había concluido con el impuesto inflacionario, revalorizando los salarios de los trabajadores y reduciendo las tasas de pobreza y desempleo, al tiempo que fomentaba el crecimiento económico, la producción y el consumo popular. Las políticas asistencialistas, finalmente, potenciaban la creación de empleo y la reducción de la pobreza. En ese contexto, lejos del capitalismo salvaje, desde el discurso verbal de Menem los planes focalizados y la estabilidad se insertaban dentro de una economía social o economía popular de mercado, que humanizaba al modelo, defendía la dignidad de los trabajadores y reenviaba al principio clásico de 
justicia social del peronismo histórico. De este modo, bajo una estabilización efectiva de la economía, el menemismo lograba incorporar un discurso de inclusión social sustantivo del pueblo.

No obstante, al examinar la interacción óntica de las interpelaciones presidenciales con el análisis de sus prácticas discursivas, observamos que se mantenían una serie de ambigüedades y discordancias fáctivas entre el plano verbal y los aspectos no meramente lingüísticos de su discurso. Por un lado, pese a aplicar radicalmente las reformas neoliberales, el menemismo mantenía algunas políticas públicas más heterodoxas. Por el otro, pese al discurso declaratorio a favor de la democracia liberal, sus prácticas decisionistas se hallaban reñidas con esta concepción procedimental. El discurso verbal conservador, además, era incongruente con el estilo presidencial frívolo y exhibicionista. Finalmente, sus apelaciones a la concepción social de la democracia y al discurso comunitarista y humanista del peronismo histórico, mostraban límites fácticos en las alianzas políticas con sectores del establishment de tradición liberal y antiperonista, la destrucción de gran parte de la industria nacional, el incremento efectivo de los índices de desocupación, inequidad social y marginalidad y las restricciones institucionales a las formas de movilización social.

Estas discordancias e incongruencias, que se expresaron en la emergencia sintomática de una serie de contradiscursos críticos, no impidieron al menemismo obtener un notable éxito político y cultural para construir un nuevo sentido común y un nuevo orden polítici y social en torno a los valores neoliberales. Así, con un discurso ultradialógico que amalgamaba elementos de diversas tradiciones de manera yuxtapuesta, condensados en la idea de estabilidad monetaria, Menem logró reprimir tendencialmente el discurso mercadointernista, nacionalista, antiimperialista y movimientista-populista, que caracterizaba al peronismo de posguerra, al tiempo que profundizaba la sedimentación de las ideas ortodoxas y la visión individualista y neoconservadora de la democracia. El menemismo se convirtió, de este modo, en una de las experiencias más profundas, pero al mismo tiempo una de las más exitosas, de implementación de las ideas neoliberales a nivel mundial, con el agregado autóctono de la Ley de Convertibilidad como factor estabilizador de la economía y la reformulación de la doctrina peronista (con su énfasis nacional-popular) a los nuevos tiempos.

El ascenso de la Alianza, bajo la presidencia de Fernando De la Rúa (1999-2001), se propuso mantener los ejes centrales de la hegemonía menemista, aunque profundizando las políticas ortodoxas, incorporando un estilo más austero y conservador y "emprolijando" al modelo con las reformas éticas e institucionalistas, promovidas por el Con- 
senso de Santiago. Los efectos de esta radicalización del neoliberalismo conservador se traducirían en un recrudecimiento de la crisis económica y social, concluyendo con los trágicos acontecimientos de diciembre del 2001 y el derrumbe del orden hegemónico. De este modo, se abriría el camino para la emergencia sintomática de nuevas interpelaciones y nuevas prácticas discursivas, que conducirían hacia horizontes diferentes.

\section{Referencias}

Aboy Carlés, G. (2001). Las dos fronteras de la democracia argentina. Rosario, Argentina: Homo Sapiens.

Clarín. 23 de julio de 1993, p. 3; 31 de julio de 1993, p. 7; 17 de julio de 1993, p. 2; 22 de julio de 1993.

Baldioli, A. y Leiras, S. (2010). Argentina en la década de la decisión política. El liderazgo neodecisionista de Carlos Saúl Menem. En S. Leiras (Comp.), Estado de excepción y democracia en América Latina (pp. 53-79). Rosario, Argentina: Homo Sapiens.

Balsa, J. (2011). Aspectos discursivos de la construcción de la hegemonía. Identidades, 1 (1), 70-90.

Bernal Meza, C. (2003). Venturas y desventuras de la Argentina: los cambios de paradigma de política exterior y su relación con los modelos de inserción. En E. C. de Rende Martins (Dir.), Relacoes Internacionais (pp. 287-317). Brasilia, Brasil: IBRI.

Bonnet, A. (2008). La hegemonía menemista. Buenos Aires, Argentina: Prometeo.

Bonetto, M. S. (2012). Una mirada sobre el pasado reciente de la democracia en el escenario regional. En M. S. Bonetto y F. Martínez (Comp.), Política y desborde (pp. 205-228). Villa María, Argentina: Eduvim.

Borón, A. (1991). Los axiomas de Anillaco. En AA.VV, El Menemato (pp. 87-143). Buenos Aires, Argentina: Letra Buena.

Ezcurra, A. M. (1998). ¿Qué es el neoliberalismo? Buenos Aires, Argentina: Ideas. 
Fair, H. (2010). Hacia una epistemología del neoliberalismo. Pensar, 5, 131-150. Recuperado de http://www.revistapensar.org/index.php/pensar/article/view/52/47

- (2013). El juego dialógico del discurso de Menem con la estructura partidaria del peronismo durante la etapa de sedimentación de la hegemonía neoliberal. De Prácticas y Discursos, 2 (2), 1-22.

Fukuyama, F. (1991). El fin de la historia y el último hombre. Buenos Aires, Argentina: Aguilar.

García Delgado, D. (1994). Estado y sociedad. Buenos Aires, Argentina: Norma-FLACSO.

—_——. (2003). Estado-nación y la crisis del modelo. Buenos Aires, Argentina: Norma.

Guiñazú, M. C. (2000). Del consenso de Washington al consenso de Santiago. Política y Gestión, 7, 79-95.

Grassi, E. (2004). Política y cultura en la sociedad neoliberal. Buenos Aires, Argentina: Espacio.

Hayek, F. (1978). Camino de servidumbre. Buenos Aires, Argentina: Alianza.

Laclau, E. (1993). Nuevas reflexiones sobre la revolución de nuestro tiempo. Buenos Aires, Argentina: Nueva visión.

————. (2005). La razón populista. Buenos Aires, Argentina: Fondo de Cultura Económica.

La Nación. 26 de junio de 1993, p. 8; 2 de mayo de 1993, p. 4.

Martínez, F. (2012). Política y conflicto: de la regulación tecnocrática a las narrativas del litigio. En M. S. Bonetto y F. Martínez (Comps.), Política y desborde: más allá de la democracia liberal (pp. 109-133). Villa María, Argentina: Eduvim.

Morresi, S. (2008). La nueva derecha argentina. Buenos Aires, Argentina: UNGS-Biblioteca Nacional.

Murillo, S. (2008). Colonizar el dolor. La interpelación ideológica del Banco Mundial en América Latina. Buenos Aires, Argentina: CLACSO. 
Página 12.7 de abril de 1993, p. 2; 30 de abril de 1993, p. 5; 15 de mayo de 1993, p. 4; 8 de junio de 1993, p. 4; 26 de junio de 1993, pp. 3-4; 26 de junio de 1993, p. 3; 30 de junio de 1993; p. 7.

Payne, M. (2003). La política importa para el desarrollo. En S. Kennedy, J. Payne, D. Zovatto y M. Mateo Díaz (Eds.), La política importa. Democracia y desarrollo en América Latina (pp. 9-26). Washington, Estados Unidos: BID.

Piñero, M. T. (14-17 de noviembre de 2001). El juego de la oca en los 90. Los discursos de Menem sobre el camino de la modernización. Ponencia presentada en el V Congreso Nacional de Ciencia Política, Sociedad Argentina de Análisis Político (SAAP), Córdoba, Argentina.

Presidencia de la Nación, Secretaría de Medios de Comunicación (1991-1993). Discursos oficiales de Carlos Menem (varios tomos). 1 de agosto de 1990; 25 de abril de 1991; 26 de abril de 1991; 2 de mayo de 1991; 23 de mayo de 1991; 14 de junio de 1991; 8 de julio de 1989; 11 de septiembre de 1989; 8 de julio de 1991; 26 de agosto de 1991; 15 de septiembre de 1992; 7 de enero de 1993; 12 de mayo de 1993; 22 de septiembre de 1993; 12 de noviembre de 1993. Buenos Aires, Argentina: Secretaria de Medios de Comunicación.

Stiglitz, J. (1998). Más instrumentos y metas más amplias para el desarrollo. Hacia el Consenso pos-Washington. Desarrollo Económico, 38 (151), 691-722. 